\title{
A articulação de enfoques quantitativos e qualitativos na avaliação em saúde: contemplando a complexidade dos objetos
}

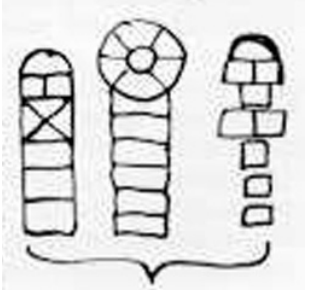

Marina Peduzzi 1

No artigo em debate, os autores concebem a avaliação em saúde como função da gestão, destinada a auxiliar o processo de decisão e apoiar as intervenções na realidade, cujo sucesso pode ser apreendido pelo(s) benefício(s) que acarreta ao(s) usuário(s) dos serviços/programas ou projetos avaliados. Portanto, o destinatário da avaliação em saúde é o usuário, o mesmo destinatário do exercício cotidiano do trabalho dos vários profissionais - gestores e produtores do cuidado direto, para os quais a avaliação consiste em uma ferramenta, um dos instrumentos por meio do qual cumprem sua responsabilidade social de agentes do trabalho em saúde.

Assim concebida e contextualizada, no entender dos autores "a avaliação torna-se um campo de trabalho propício para a aplicação transdisciplinar dos conhecimentos (da área da saúde)", visto que abarca objetivos mais compreensivos que não são contemplados pela adoção de modelos préestabelecidos e rígidos.

De fato, conta-se com uma significativa literatura acerca da interdisciplinaridade e da transdisciplinaridade como projetos que permitem abarcar a complexidade dos objetos e entendo que os autores inserem a avaliação em saúde no âmago dessa discussão, embora preocupados sobretudo com a sua aplicabilidade no cotidiano dos serviços. Esta ressalva faz-se necessária, visto que a produção teórica sobre interdisciplinaridade $e$ transdisciplinaridade trata-as como problemáticas atinentes, particularmente, à investigação científica e ao ensino acadêmico, configurando-as como uma construção discursiva eminentemente epistemológica (Japiassu, 1976; Minayo, 1994; Spink, 1992; Schramm, 1994; Nunes, 1995; Almeida-Filho, 1997; Ayres, 1997; Peduzzi, 1998).

\footnotetext{
${ }^{1}$ Professora do Departamento de Orientação Profissional, Escola de Enfermagem, Universidade de São Paulo, USP. <marinape@usp.br>
} 

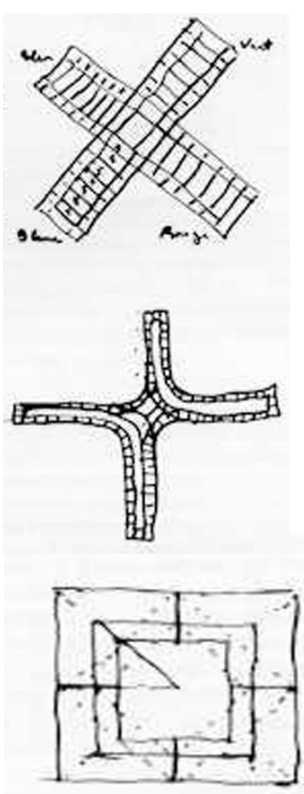

Há, portanto, que se considerar a distinção conceitual entre ambas, apresentadas pela literatura como diferentes possibilidades de relações disciplinares. Nesse debate, a transdisciplinaridade representa uma etapa superior que se sucede à interdisciplinaridade, que situa as relações ou reciprocidades entre as diversas disciplinas no interior de um sistema total, tomando por base uma axiomática geral compartilhada capaz de instaurar uma coordenação, em vista de uma finalidade comum (Japiassu, 1976; Nunes, 1995; Almeida-Filho, 1997).

Consideradas essas questões conceituais, entendo que a proposta dos autores refere-se a uma abordagem interdisciplinar da avaliação em saúde, na qual buscam obter uma coordenação e colaboração entre as diferentes áreas de conhecimento para melhorar a qualidade de resposta aos interesses dos usuários. Os próprios autores chamam a atenção para que cada processo de avaliação tenha um desenho próprio e único pertinente às perguntas formuladas, utilizando os recursos das distintas disciplinas para subsidiar efetivamente as "decisões em jogo". Nessa perspectiva, estão mantidas as especificidades de cada campo disciplinar e a avaliação é compreendida como uma área de aplicação desses conhecimentos.

Assim, coloca-se a necessidade de incorporar a interdisciplinaridade na avaliação em saúde. Um segundo aspecto importante da proposta $e$ imediatamente relacionado a este primeiro, é a sua potencialidade no sentido de permitir uma avaliação mais ampla e multidimensional, visto que articula enfoques quantitativos e qualitativos.

Essa articulação é promissora à medida que possibilita contemplar a complexidade dos objetos da avaliação em saúde, referidos à organização do trabalho; à eficiência, eficácia e efetividade na prestação de serviços; ao processo saúde-doença; à interação usuário-serviço e usuário-profissional e outros.

Tomar em consideração a complexidade dos objetos de estudo e de intervenção significa considerar que não são lineares mas sim múltiplos $e$ sintéticos, ou seja, os vários aspectos que configuram o objeto recortado para avaliação guardam, entre si, relações de reciprocidade e mútua influência. Além disso, considerar a complexidade quanti-quali da avaliação implicará em reconhecer a relação sujeito-objeto como intrínseca ao conhecimento e este como possibilidade de apreender os fenômenos por meio de um processo que, ao mesmo tempo, disjunte e associe, concebendo os vários níveis de emergência da realidade sem reduzi-los às unidades elementares e às leis gerais (Morin, 1990).

A integração dos enfoques quantitativo e qualitativo na avaliação em saúde também permite contemplar a constituição das práticas de saúde como trabalho reflexivo em serviços. Este tem como característica, por um lado, buscar reconhecimento, respeito e preservação da particularidade, individualidade e variabilidade das necessidades dos usuários e, por outro lado, aplicar certas regras, conhecimentos e valores gerais. Ou seja, o serviço em saúde somente será bem-sucedido se produzir um equilíbrio entre esses dois aspectos, considerando, ao mesmo tempo, a "especificidade do caso" e a "generalidade da norma". A aproximação sucessiva do objeto de avaliação por meio de abordagens quantitativas e qualitativas permitirá abarcar essa 
complexa dinâmica operacionalizada pelo agente do trabalho, isto é, permitirá tanto identificar e explicar as relações entre os objetivos e os resultados alcançados no recorte específico em avaliação, quanto compreender em profundidade o significado dessas relações.

Os autores do artigo consideram que a avaliação está baseada também nos conhecimentos e práticas dos profissionais e, assim, tomam em consideração os aspectos destacados acima. $O$ trabalhador exerce e interpreta seu trabalho com autonomia profissional, visto que fundamenta suas ações em saberes técnicos $e$ pode introduzir inovações no processo de trabalho, pois a aplicação da técnica é permeada pela intersubjetividade. Isto é, por meio do dialogo entre usuárioprofissional e entre os profissionais da equipe de saúde, o agente reconhece as necessidades de saúde dos usuários e pode inovar no que se fizer necessário. $\mathrm{O}$ que se quer ressaltar e parece contemplado pela proposta é que os profissionais tanto reiteram a técnica estabelecida, quanto inovam naquilo que o "estabelecido" não permite compreender/intervir, $e$ ambas as esferas, $o$ esperado e o efetivamente realizado, devem ser objeto e parâmetro para a avaliação.

Embora não esteja diretamente referida, a utilização de técnicas de pesquisa quantitativa e qualitativa possibilita a avaliação dos processos de trabalho, tanto no que diz respeito às ações $e$ aos resultados, quanto à interação dos sujeitos envolvidos. Retomando o primeiro aspecto da proposta e com isso finalizando estes breves comentários, a análise desse material empírico, coletado com base em distintas técnicas e fontes, requer a articulação de quadros teórico-conceituais diversos, numa perspectiva interdisciplinar da avaliação em saúde.

Referências bibliográficas

ALMEIDA-FILHO, N. Transdisciplinaridade e saúde coletiva. Ciência e Saúde Coletiva. v. 2, n. 1/2, p. 520, 1997.

AYRES, J.R. de M. Deve-se definir transdisciplinaridade? Ciência e Saúde Coletiva. v. 2, n. 1², p. 36-38, 1997.

JAPIASSU, H. Interdisciplinaridade e patologia do saber. Rio de Janeiro: Imago, 1976.

MINAYO, M.C.S. Interdisciplinaridade: Funcionalidade ou utopia? Saúde e Sociedade. v 3, n 20, p. 42-63, 1994.

MORIN, E. Ciência com consciência. Lisboa: Europa-América, 1990.

NUNES, E.D. A questão da interdisciplinaridade no estudo da saúde coletiva e o papel das ciências sociais. In: CANESQUI, A.M. (Org.) Dilemas e desafios das ciências sociais na saúde coletiva. São Paulo: Hucitec, 1995.

PEDUZZI, M. Equipe multiprofissional em saúde: a interface entre trabalho e interação. Campinas, 1998. 254p. Tese (Doutorado). Faculdade de Ciências Médicas, Universidade Estadual de Campinas. SCHRAMM, F.R. A ética natural. Aula proferida na disciplina História e Paradigmas do Conhecimento em saúde, Pós-Graduação em saúde Coletiva/FMC/Unicamp, Campinas, 1/julho/1994 (mimeo). SPINK, M.J.P. Saúde: um campo transdisciplinar? Rev. Ter. Ocup. USP. v 3, n 1⁄2, p. 17-23, 1992.

PALAVRAS- CHAVE: Avaliação; tomada de decisão; serviços de Saúde. KEY WORDS: Evaluation; decision making; health services.

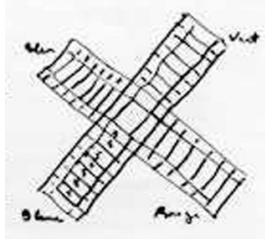

